\title{
What is Wrong with Silence in Intercultural Classrooms? An Insight into International Students' Integration at a UK University
}

\author{
Sihui Wang ${ }^{\mathrm{a},{ }^{*}}$, and Marta Moskal ${ }^{b}$ \\ ${ }^{a}$ University of Glasgow, United Kingdom; ${ }^{b}$ Durham University, United Kingdom \\ *Corresponding author: Email: s.wang.3@ research.gla.ac.uk \\ Address: Room 683, School of Education, St Andrews Building 11 Eldon Street, Glasgow G3 6NH
}

\section{Introduction}

The internationalization of higher education and growth of international student mobility make higher education classrooms culturally and linguistically more diverse than ever, especially among postgraduate students (Brown and Holloway 2008; Gu, Schweisfurth, and Day 2009; Yu and Moskal 2019). However, recent research reports a common tendency for international students to be silent in the Western English-medium classroom (Choi 2015; Zappa-Hollman and Duff 2015; Morita 2004), identifying language competence and cultural difference as two main barriers to participation (Zhou, Knoke, and Sakamoto 2005). International students often bring a different cultural understanding of classroom interaction norms and conventions (Dippold 2015). Grounded in the theoretical framework of "community of practice" (Lave and Wenger 1991), this paper perceives international students' verbal participation as a "dynamic, socially situated process" (Duff 2010, 169) and classrooms as communities, in which students develop "an

evolving form of membership" as they "change in how they participate in a community through the multiple social relations and roles they experience" (Lave and Wenger 1991, 53). In short, this study investigates how community members interact with and adjust to each other in order to create an equal classroom atmosphere.

\section{University Classroom as A Community of Practice}

Advocating the social nature of learning, Lave and Wenger (1991) proposed community of practice to emphasize the dynamic of changing relationships between learners and particular communities, in which they are involved. Wenger (1998, p.73) further extended the notion with three defining characteristics as "mutual engagement", "joint enterprise" and "shared repertoire". Among these three dimensions of the relation, mutual engagement entails common passion, engaged diversity and cooperation while joint enterprise refers to regular interactions among the community members and mutual accountability developed during the process. Shared repertoire indicates the resources that community members share with each other such as previous experiences, concepts and styles.

The examined context of classrooms in higher education is studied as a community of practice, holding an aggregate of home students and international students who are mutually engaged in the specific subject of the classroom through shared classroom activities using a shared repertoire of resources (Dippold 2015). Multicultural classroom in internationalized higher education is a setting of complexed nature with the involvement of language issue, different cultures and interaction patterns. Duff (2007, p.315) highlights the important roles of sense of community and the influence of "old-timers" such as instructors and home students who are used to the educational systems. She claims that "joint enterprise or mutual engagement in activity by 'old-timers' and 'newcomers' provides the foundation for learning, and that practice and community belonging are key aspects of learning and identity formation." 
This paper seeks to contribute to a growing stand of literature that examines international students' integration in the community of the university classroom, with a particular focus on silence.

\section{The Concept of Silence}

International students' silence in classrooms has been identified in many previous studies. For example, treating silence as a barrier to learning in US university classroom, Choi (2015) attributed the reticence of two Korean students to limited English proficiency, different classroom gestures and culture. By contrast, in a similar context of US university classroom, Tatar (2005) recognized the importance of silence while examining four Turkish international students' learning and revealed that silence performed the function of a face-saving strategy, a sign of respect for authority and a means of participation. Furthermore, Kim et al. (2016) explored Japanese students' socio-cultural perceptions of silence and called for legitimatizing silence as a teaching strategy and a form of engaged participation. The existing literature usually linked international students' reticence to cultural differences and English communicative competences ( $\mathrm{Ha}$ and $\mathrm{Li} 2014$ ) as silence is often attributed to individual characteristics of the students. However, little research has been conducted on how such language based inhibition may be compounded by other contextual elements, such as "reciprocal cultural familiarity" and power differentials between different languages, cultures and knowledge (Zhou, Knoke, and Sakamoto 2005, 288).

In Moskal and Schweisfurth's study (2018), international postgraduates talked not only about the difficulties of engaging across the differences of language and cultural background but also about hidden prejudices related to perceptions of otherness on both sides. Kurzon (1997, cited in Nakane 2006) distinguished different types of silence in different contexts, "intentional" and "unintentional". Intentional silence is usually a deliberate strategy to cope with a certain situation and unintentional silence describes unwilling silence, which often comes with frustration and embarrassment. A context oriented analysis of students' cross-cultural experiences has been advocated (Cheng 2000; Kubota and Lehner 2004), and we follow this approach in this paper. Informed by the social learning and community of practice theory, we explore silence in a specific context, namely a classroom setting of a UK university, rather than assuming it is predetermined by students' cultural and educational backgrounds. We examine the concept of silence as a fluid and socially situated phenomenon and present the voices behind the silence by discussing three student cases.

\section{Methods}

This paper draws on an ethnographic case study among ten postgraduate students from seven different countries, conducted by the first author in an established university in the UK during the 2016-17 academic year. Ethnographic techniques allow the study to capture the multiplicity and fluidity of the participants' classroom experiences (Bryman 2012). The fieldwork generated eighty hours of interviews, seventy-eight sets of field notes and sixty reflective journals. Classroom observation was used to record the classroom dynamics, teaching practices and focal students' behaviors. Sitting at the back of the classroom, the first author took non-participant observation and noted down details in observation protocols, focusing on participants' behaviors and interactions with others. Semi-structured interviews were also conducted with the focal students $(n=10)$, their instructors $(n=12)$ and their peers $(n=12)$ to explore the phenomenon from different perspectives (Silverman 2013). Instructors were lecturer and tutors who led the class. Their peers who had interaction with the focal students both inside and outside the classroom were selected.

Student interviews consisted of immediate short interviews before or after the class as well as three rounds of formal one-hour interviews throughout the academic year. Additionally, focal students kept reflective journals to document significant events. Interviews with their instructors and peers were carried out at the end of the course, focusing on their experience of interacting with international students and impressions of the influences of target 
participants on their job and study respectively. The data was coded, categorized and summarized under the guidance of thematic analysis (Patton 2015). Interceder's review and triangulation of multiple perspectives increased the trustworthiness and creditability of the analysis process (Bryman 2012). Pseudonyms were applied for all participants' and courses' names to protect participants' confidentiality and anonymity.

\section{Research Findings}

The findings present various and inter-connected reasons leading to focal students' reticence in class, as well as the co-constructed nature of silence (Morita 2004). This section outlines the overall themes drawn from the research project and illustrates each theme with one specific case in context.

\section{Misinterpretation of Silence}

The research findings revealed different conceptualizations of silence among different classroom community members. Compared with the focal participants, their native-English-speaking peers attributed greater significance to oral participation in classroom activities. To some of them, oral participation was such an essential part of the learning process that they misunderstood silence as international students' disinterest, lack of preparation or insufficient knowledge. This adversely affected the focal students' integration in the classroom context, in some extreme cases conflicts and tensions aroused as international students and their peers blamed each other for the inactive atmosphere or learning inefficiency. Haijun's experience in the Course "International Communication" presented the effects of different conceptualizations and expectations on their classroom interactions and showed how the native-Englishspeaking peers perceived international students' silence.

Haijun, a 26 years old Chinese student, came to pursue his master's degree in International Communication after working as a documentary editor in China for three years. The course took the form of seminar with nineteen students, including fourteen Chinese, one Indonesian, and four British. A common observation of the class was the silence of most of the Chinese students, as noted in all the field notes of this course. By contrast, the other students were more active during classroom activities. Haijun reported different reasons for being silent, related to developing perceptions of verbal participation at different stages. He reflected that he was eager to speak up in the beginning, when he was impressed by the interactive modes of class in the new learning context (Journal 1). When Haijun was asked "Why do you speak less as this semester goes on?" he answered,

I only feel motivated or inspired to speak up when someone comes up with original and in-depth ideas. I have not met any students like this yet in this class. I only participate when I feel my opinions will contribute to the teaching content and may benefit other students. (Interview 1)

Haijun did not like speaking up for the sake of drawing attention or just making some noise in class (Journal 5). He felt discussions generally remained at a superficial level.

Haijun's British peer Tracy expressed a different opinion. Tracy is a mature student from England who had sevenyear work experience before her studies. Tracy treated verbal participation as a critical part in the learning process. She felt "The participation part of the seminar is when the information really sticks in your head." Unfortunately, Tracy dropped out as she found it difficult to learn in the specific classroom atmosphere,

There was no dialogue. There was no participation in the seminars. It made me feel very unhappy and I had to change because I didn't feel I was getting much out of the classes, because everybody was quiet. 
Nevertheless, Tracy explained it was a difficult decision and she felt sorry for the international students because she sympathized with their learning difficulties. However, she found it unacceptable to have such a quiet class and she interpreted the silence of international students as a lack of "background knowledge", "preparation for discussion" and "language barriers". Although Haijun did not interpret Tracy's dropout personally and expressed his understanding of Tracy's decision. However, he felt that Chinese students were looked down upon as well:

I think she must think communicating with people from other countries is more important. They chose to leave. It's their choice. I think more or less; Chinese students are discriminated overseas. It's not because what we did but just because of the big population of Chinese students. Of course, they will not say anything rude or offensive, but you can feel they try to avoid you. (Haijun, Interview 2)

Participants' perceptions of classroom participation had significant influence on their classroom performances and efforts to speak up (Guo and Chase 2011). Haijun and Tracy had little reciprocal cultural and educational familiarity that caused lack of communication and mutual understanding.

\section{Negotiation of Membership}

International students' silence was also closely related to their membership in the classroom community. Some students chose to remain silent in discussions because they felt marginalized by their native-English-speaking peers and they did not feel there was space or time left for them. Their membership in the classroom communities was related to the development of participation modes. A comparison of Mary's experience in the courses "Educational Inquiries" (EI) and "Adult Education" (AE) shows how the membership to specific class communities affects participation patterns.

Mary, a 27 years old student from Mexico got a bachelor's degree in Psychology, and she had two years' teaching experience for children with special needs. Mary valued the importance of verbal communication in class, but she did not manage to speak up in all the classes. She admitted that her English proficiency and knowledge of the subject had a great effect on her oral classroom participation, but she thought "It's more about if I feel comfortable in that group" (Interview 3). Mary felt easier to speak up in AE than in EI. The sense of membership in these different class communities had a significant influence on Mary's participation.

Both courses had a lively atmosphere and involved around twenty students with diverse cultural and linguistic backgrounds. The difference was that the EI course was usually dominated by the native English speakers while almost everyone spoke up in the AE course as documented in the field notes. There was a lack of international students' integration in EI, evidenced by the fact that since the first presentation session, when students were divided into three groups, they sat in the same group for the rest of the term. The native English students sat in one group while Mary formed a group with four Chinese students. There were hardly interactions among the three groups. A clear divide could be observed between the native English and non-native English speakers, not only in their seat positions but also in their participation frequencies. Mary complained about the native English students being dominant and insisting on their opinions. Mary always felt short of time and "space" to participate in this class as she stated that,

In this class, I feel it's more dominated by the native English speakers. So, there is not enough time, like room to speak. And they sometimes, even just end up speaking, answering themselves like between them. So, it doesn't feel like there is room to participate. (Interview 2) 
In contrast, Mary described the course on AE as "where I have seen more people participate" (Interview 3). Mary confessed that she had little background knowledge of this subject, but she enjoyed studying with this group of peers as a community. Even though Mary was the only student from a different major, she felt included and integrated into this class. She felt a sense of belonging to the class where everyone knew each other's name. Mary replied to question "What is your impression of Course AE?" as below,

I think everybody was very interested in everyone's opinion in Course AE. Sometimes I think, in other classes like Course EI, I feel like people are just waiting for you to finish. You know they don't really like interested. They were interested in your opinion. It was more like a group. (Interview 3)

Mary achieved integration in the AE course, which made her feel secure and motivated to contribute to the discussions. Mary's different experience in these two courses underscores the importance of group membership and belonging within the class to provide a supportive environment for students' verbal participation.

\section{"Silence as my way of participation"}

Kim et al. (2016) argue that verbal participation is not the single form of engaged learning and that silence can also be treated as a form of participation. Following Kurzon's categories of silence, Haijun and Mary represented the "unintentional" type because they were reluctant to participate, while Qiang's case was more proactive and suggested "intentional" silence, which could be seen as pedagogy rather than a deficient participation mode. Qiang was a 24 years old Chinese student. He studied Accounting and he worked in a bank for a year before moving to the UK for further study. Qiang was completely silent throughout the whole academic year in both lectures and tutorials. However, he was an attentive listener and usually sat in the front listening carefully and taking notes. Qiang has been arguing throughout the study that silence was "my way of participation" (Journal 8). He did not consider silence in a class as a problem. He had his own understanding of a good lesson when he compared his experience in the two tutorials, as shown below.

Qiang was observed during two tutorials, one in International Accounting (IA) and one in International Finance (IF). The classroom atmosphere of the IA tutorial was more dynamic than that of the IF. Most of the time, Qiang remained silent in both tutorials. Nonetheless, Qiang preferred the tutorial of IF over that of IA since his criterion of a good lesson was "the structure of the content" rather than the interactive format. He thought tutorial IF was well organized and structured. In contrast, although tutorial IA was more dynamic, Qiang did not feel that he acquired anything from the open discussions.

Qiang achieved Merit as his final average grades and the highest mark for a group project. Although he did not participate verbally in class, he demonstrated good understanding of the teaching content and assignment. Qiang described, "I focus more on the result than on the process. I know clearly what I want". He had no doubt of himself as a "competent learner". He understood that he had strong independent learning skills. When asked "What do you think of the role of speaking up or group discussion in the process of your learning?” Qiang responded,

I might be slow in the beginning but it's because I always have deep thinking about questions. It will be stuck in my head after I figure it out on my own. I will be confused if I learn by discussing with others. (Interview 3)

\section{Conclusions and Implications for Practice}

This paper reveals the tensions between international students and their peers in the classroom resulting from different expectations and perceptions of classroom participation. Comparing and contrasting the selected participants' 
experiences, we explain their different socialization processes by mapping out factors that lead to their silence and that promote their participation. Consistent with previous research, our findings indicate that linguistic and cultural factors greatly affected students' classroom reticence. However, it is important to discuss the context and link it to other influential factors like participants' negotiation of membership of community of practice. "Intentionally" silent students chose to keep quiet in class, viewing silence as acceptable and normal behavior, in contrast, "unintentionally" silent students found verbal participation challenging.

Fostering an appreciation of diversity in the classroom requires the open exchange of ideas and experiences of students from different backgrounds (Zhou, Knoke, and Sakamoto 2005, 307). Mutual understanding among students should be encouraged to promote students' cooperative learning. One potential way to achieve this can be an induction program or the instructor's interventions to promote an open exchange of opinions and experiences of students from different backgrounds. Some of the observed departments had an induction program, however, it was usually about the introduction of staff and assessments.

A brief introduction to the classroom conventions would help students to understand the learning environment better. Hollander (2002) defines classroom participation as a collective responsibility of the class rather than just an individual responsibility. It is neither international students' responsibility to adapt to the new learning environment or their peers' or instructors' obligation to compromise. This should be an interactive and mutually inclusive process. It is important to promote an appreciation of diversity in the classroom community to legitimize different participation modes. Ha and $\mathrm{Li}$ (2014, p.245) argue for "the need to optimize silence as pedagogy" to recognize learning diversity rather than to compromise for "a shared behavior". This is not to encourage students to keep silent, but rather to remove the misunderstanding and negative stereotypes of silence as non-participation or passive learning. To facilitate the formation of a positive classroom atmosphere, more interactions and social activities, inside and outside the classroom, should be encouraged and arranged by higher education practitioners to get students to know each other and thus develop a sense of community. Zhou, Knoke and Sakamoto (2005) argue that familiarity with peers and instructors can contribute to "sense of safety" and "sense of belonging". When international students feel they are members of the class and their ideas are welcomed, they would make extra efforts to contribute to the discussion.

\section{References}

Brown, Lorraine, and Immy Holloway. 2008. "The Adjustment Journey of International Postgraduate Students at an English University." Journal of Research in International Education 7 (2): 232-49. https://doi.org/10.1177/1475240908091306.

Bryman, Alan. 2012. Social Research Methods. 4th ed. New York: Oxford University Press.

Cheng, Xiaotang. 2000. “Asian Students' Reticence Revisited.” System 28 (3): 435-46. https://doi.org/10.1016/S0346251X(00)00015-4.

Choi, Jung Yun. 2015. "Reasons for Silence: A Case Study of Two Korean Students at a U.S. Graduate School." TESOL Journal 6 (3): 579-96. https://doi.org/10.1002/tesj.209.

Dippold, Doris. 2015. Classroom Interaction: The Internationalised Anglophone University. New York. Palgrave Macmillan.

Duff, Patricia a. 2007. 'Second Language Socialization as Sociocultural Theory: Insights and Issues'. Language Teaching 40 (04): 309-19. doi:10.1017/S0261444807004508.

Duff, Patricia a. 2010. "Language Socialization into Academic Discourse Communities." Annual Review of Applied Linguistics 30: 169-92. 
Gu, Qing, Michele Schweisfurth, and Christopher Day. 2009. "Learning and Growing in a 'foreign' Context: Intercultural Experiences of International Students." Compare $40 \quad$ (1): 7-23. https://doi.org/10.1080/03057920903115983.

Guo, Shibao, and Mackie Chase. 2011. "Internationalisation of Higher Education: Integrating International Students into Canadian Academic Environment." Teaching in Higher Education 16 (3): 305-18. https://doi.org/10.1080/13562517.2010.546524.

Ha, Phan Le, and Binghui Li. 2014. "Silence as Right, Choice, Resistance and Strategy among Chinese 'Me Generation' Students: Implications for Pedagogy.” Discourse: Studies in the Cultural Politics of Education 35 (2): 233-48. https://doi.org/10.1080/01596306.2012.745733.

Hollander, Jocelyn A. 2002. "Learning to Discuss: Strategies for Improving the Quality of Class Discussion." Teaching Sociology 30 (3): 317-27.

Kim, Soonhyang, Burcu Ates, Yurimi Grigsby, Stefani Kraker, and Timothy A Micek. 2016. "Ways to Promote the Classroom Participation of International Students by Understanding the Silence of Japanese University Students." Journal of International Students 6 (2): 431-50.

Kubota, Ryuko, and Al Lehner. 2004. "Toward Critical Contrastive Rhetoric.” Journal of Second Language Writing 13 (1): 7-27. https://doi.org/10.1016/J.JSLW.2004.04.003.

Kurzon, Dennis. 1997. Discourse of Silence. Amsterdam: John Benjamins.

Lave, Jean, and Etienne, Wenger. 1991. Situated Learning: Legitimate Peripheral Participation. Cambridge: Cambridge University Press.

Morita, Naoko. 2004. "Negotiating Participation and Identity in Second Language Academic Communities." TESOL QUARTERLY 38 (4): 573-603. https://doi.org/10.2307/3588281.

Moskal, Marta, and Michele Schweisfurth. 2018. "Learning, Using and Exchanging Global Competence in the Context of International Postgraduate Mobility." Globalisation, Societies and Education 16 (1): 93-105. https://doi.org/10.1080/14767724.2017.1387768.

Nakane, Ikuko. 2006. "Silence and Politeness in Intercultural Communication in University Seminars." Journal of Pragmatics 38 (11): 1811-35. https://doi.org/10.1016/J.PRAGMA.2006.01.005.

Patton, Michael Quinn. 2015. Qualitative Research \& Evaluation Methods : Integrating Theory and Practice. 4th ed. CA: Sage.

Silverman, David. 2013. Doing Qualitative Research: A Practical Handbook. SAGE Publications Limited.

Tatar, Sibel. 2005. "Why Keep Silent? The Classroom Participation Experiences of Non-Native-English-Speaking Students." Language and Intercultural Communication $5 \quad$ (3-4): $284-93$. https://doi.org/10.1080/14708470508668902.

Wenger, Etienne. 1998. Communities of Practice: Learning, Meaning, and Identity. Cambridge: Cambridge University Press.

Yu, Yun, and Marta Moskal. 2019. "Missing Intercultural Engagements in the University Experiences of Chinese International Students in the UK." Compare: A Journal of Comparative and International Education, 49 (4), $654-$ 671.

Zappa-Hollman, Sandra, and Patricia A. Duff. 2015. "Academic English Socialization through Individual Networks of Practice.” TESOL Quarterly 49 (2): 333-68. https://doi.org/10.1002/tesq.188.

Zhou, Yanqiu Rachel, Della Knoke, and Izumi Sakamoto. 2005. "Rethinking Silence in the Classroom: Chinese Students' Experiences of Sharing Indigenous Knowledge.” International Journal of Inclusive Education 9 (3): 287-311. https://doi.org/10.1080/13603110500075180. 